\title{
Practical Study of University Sunshine Sports Instructors' Work
}

\author{
Jiaping Deng ${ }^{1}$ \\ Physical Education Department \\ Shanghai Polytechnic University \\ Shanghai, China \\ jpdeng@sspu.edu.cn
}

\author{
Yingfeng $\mathrm{He}^{2 *}$ \\ Physical Education Department \\ Shanghai Polytechnic University \\ Shanghai, China \\ heyingfeng@sspu.edu.cn
}

\begin{abstract}
Analysis of university in carrying out the sunshine sports, how to around college talents training objectives ,build for two-level academy "sunshine sports instructors " working mechanism, management system and evaluation mechanisms. And make full use of the school for nearly three years' work practice in sunshine sports instructors, to explore in depth in how to use the development function of sunshine sports instructors in developing key student of academy sunshine sports and how to improve the improvement ,supervision and guidance of academy sunshine sports instructors.
\end{abstract}

Keywords-University; Sunshine sports instructor; Affiliated academy

\section{INTRODUCTION}

Chinese education is facing new situation and new requirements of Chinese college education. College physical education, as a part of college education, is a weakness in the quality education and cultivating physical and mental health. Students' constitution and abilities of sports is deficient now. The main factor is lack of encouragement, knowledge of science if physical education and holding sports activities and constant support from competent department. Therefore, it is really a problem how college physical education completely exerts its special function and how to treat after-school activities as extra P.E. classes [1]. This article discusses how to establish a kind of work system which named Sunshine Sports Instructor in Sunshine Sports Activity in order to enable Sunshine Sports Instructor to cooperate with secondary academies and train elites in guidance departments and academies. This aims to provide revolution of college education with some theories and experiments.

\section{THE NECESSITY OF SUNSHINE SPORTS INSTRUCTOR}

\section{A. The Sunshine Sports Activity}

According to the requirement of file Organizing shanghai students' Sunshine Physical Education Competition which is released by departments like Shanghai School board, we realized that it is a turning point that college physical education is located in the time between students going to the society from school. Combining the actuality and character of the school, except in the P.E. classes, developing Sunshine Sports Activity should be treated as a main job and sally port in the school. School ought to insist on the organizational policies like "having a foothold in the school and facing all of the students" and "Everyone has events; every class has activities; School creates its specialty." Every year, school carries into execution and makes a project on Sunshine Physical Education Competition. And then, academies and departments make their own plans based on the project.

The Sports ministry sends Sunshine Sports Instructors to each academy and department. It is based on the Sunshine Physical Education Competition Project and helps secondary academies to formulate a project of sports activities and competitions in a semester. The Sports ministry should oversee practice of the project and train the elites in the academies at ordinary times including telling the meaning of responsibility, group work and competition [2].

\section{B. Aim and Target}

While starting the project, it is necessary that the project should actively lead students and organization to obtain 2 goals It means the project helps students to establish a concept of "health first" and develop a habit which insists on running 1 hour every day. Treating mass competition of Physical Education as a platform, the project can establish a long-term system of activities on campus and realize the target of "everyone has events; every class has team; every competition is constant." Shuttlecock should be treated as a main point within executing the target of running 1 hour every day and student ought to practice it every class. Competition of shuttlecock between class and class, grade and grade and academy and academy will be held every week. At the same time, after-school activities which contain high value and students are fond of can be increased in order to guarantee the quality and number of P.E. class, morning exercise, extracurricular activities and all kinds of competitions.

The aspect of students' which includes joining physical exercise and constitution will be enhanced in order to guarantee that students do join the exercise. 


\section{SETTING UP AND SUPERVISING THE DEVELOPMENT OF} THE PROJECT

\section{A. Sunshine Physical Education Instructor}

Sunshine Physical Education Instructor means the person who is under combining teacher of Sports ministry and a secondary academy. The establishment of the system is to make full use of physical education teachers in the sports knowledge and expertise to guide students to participate in physical exercise so that they learn the scientific exercise methods, and gradually develop the habit of scientific fitness. Students' health can be constantly improved while guiding students to learn organizing sports competitions and training their organizational skills. The project can be developed fluently [3].

\section{B. The main job of Sunshine Sports Instructor}

- Training elites. After the implementation of the guidance of the departments and Institutes, Sunshine Sports Instructors make the full use of physical education activities [4], group competition, sports elective courses and other activities platform for the Ministry of Sunshine sports activities. They can cultivate sports and group activities elites, network of class group activities. Project can be successfully developed.

- Guide and inspection. Sunshine Sports Instructors should always communicate with the department, the college student in charge of the work of the party branch secretary, student sports minister, student sports elites in order to guide the college to develop community activities to plan to solve the problems in the group activities. They can strengthen the process of monitoring the implementation of group activities and earnestly promote the development of college sunshine sports

- Summarize and improve. In the work, Sunshine Sports Instructors ought to pay attention to sum up experience and found the problems in the process so as to give timely correction. Outstanding performance of the activities of the advanced collective and personal deeds to timely report [5]. All the activities and graphic information, according to the requirements of the summary, can become the evidence which will be used in year-end selection of sunshine sports activities. Summary improves the effectiveness of sunshine sports so that the project benefits to every student.

In order to strengthen the "sunshine sports instructor" work process management and enable Sun Sports Instructors and secondary colleges to guide the work more effective, the Ministry of Sports has also developed a "sun sports instructor work manual." Sunshine sports instructor system actively promotes the project. It played an affection issued, under the upload" link role, a guiding role of expert sand a guiding and supervision role [6].

\section{The MANAGEMENT AND EVALUATION}

\section{A. The management of Sunshine Sports Instructor}

- The school sports ministry appoints a deputy director of the sports department to be responsible for the work which is managed by the sports group guidance team. Each year the sports ministry for the physical education teachers to hire "sunshine sports instructor" (for a year). The sports ministry group is responsible for arranging the sunshine sports instructor to contact the department and school. It is also responsible for the work of the plan and implementation steps like job summary, material summary and rating. The college arranged a counselor as part of the college sunshine sports work liaison [7]. They all will be scored by their work in each semester.

- The group work guidance team strengthens the contact with Sunshine Sports Instructors and faculties, colleges, and constantly understands their work to carry out the situation [8]. It creates the necessary conditions to coordinate in order to support and help them do the work of the sun sports instructor.

\section{B. The Evaluation of Sunshine Sports Instructor}

- Evaluation is divided into three indicators. Semester of sun sports instructor evaluation is a 100 points system. The development plan is 20 points. The organization is 10 points. Carrying out activities is 40 points. The winning of competition is 10 points. Left 20 points in the work will be evaluated by 5 different aspects.

- Refining evaluation indicators based on second-level indicators and various aspects of evaluation can become a more comprehensive reflection of the sports instructor under the work of the Institute and the sunshine sports promotion plan to complete the situation.

- Sports instructors need to work in accordance with the requirement. The work of the Sunshine Sports Instructor is evaluated at the end of each semester. The sports ministry scores according to the relevant documents and materials of the Sunshine Sports Instructors and the feedback of the various aspects of the College (student and teacher level).

- Evaluation of the Academy promotes the establishment of sunshine sports organizations (College Sunshine Sports Leading Group under the competition group, activities group, publicity group, office, college belongs to the class of sunshine sports liaison, by the class sports committee concurrently).

- Method level of evaluation is divided into the ratio of 3: $3: 4$ and 3 prizes. Sports ministry will give a reward and appreciate the prize winners.

- Participating in the sun sports instructor work and make outstanding achievements is the priority of the future promotion. 


\section{Assessment Co of Sunshine Sports Instructors}

- Completing the Academy Sunshine Sports Promotion Program and the academic year and semester to carry out sports activities and competition plan.

- College Sunshine Sports Leading Group; Sunshine Sports Working Group (with the College Student Sports Department) (under the competition group, group activities group, publicity group, office, etc.);College of the class of sunshine sports liaison (by the class sports committee concurrently).

- Organizing and guiding the sports competitions organized by the college to participate in the school organization; Organization, guidance of the college to carry out mass sports and sports competitions, students participate in the high rate of activities in the form of rich; Guiding the sports activities and competitions of the students at the class level; Completing the school large-scale sports competition task; Organizing the event and participate in the volunteer.

- School sports competition award.

- Annual summary; College to carry out the sun sports situation list; the "plan" and "grade book" of the corresponding activities; Corresponding picture and image data.

\section{Assessment Indicators of Sunshine Sports Instructors}

- Planning (20 points). Checking the completion of the Academy's Sunshine Sports Promotion Program, complete the plan on time, do not complete the plan on time deduction 4 points, no plan not to score.

- Institution (10 points). Checking the school sunshine sports leading group organization to complete the situation (to provide the list of institutions) 2 points; sun sports work group and set up under the group of six points; college belongs to the class sunshine sports liaison list 2 points.

- Activities (40 points). View the "Sunshine Sports Instructor Workbook" to guide the activities of the College list 10 points; listen to the college feedback 5 points;(Including: dragon boat races, shuttlecock games and other times); to undertake several events, to participate in the school sports activities and activities (including the number of times) 10 points; Volunteer activity 5 points.

- Winning in the competition (10 points). During the year to participate in the event award (sports competition to take the group ranking) each 1 points, out of 6 points; photography, essay and other competitions won the individual ranking, each 1 points, out of 4 points.
- Summarizing the work (20 points). Annual summary detail, complete 6 points. There are complete college to carry out sunshine sports list ("plan" and "results") 6 points; all activities to carry out the picture, image data 8 points; missing a project picture, image data deduction 1 point.

\section{SUGGestions}

- Sunshine sports instructors selected by sports ministry should have a strong sports professional background in order to play a core guiding role in carrying out the project.

- Sunshine sports instructors should have the spirit of pioneering and innovative spirit. In the background of carrying out the dragon boat and shuttlecocks. They should focus on student health standards, exercise value, rich content and the creative form of novel extracurricular sports activities. It can gradually develop the characteristics of college sunshine sports.

- Sunshine sports instructors in the work should give full play to the college student union and elite in the sports ministry. They should pay attention to the organization launched by the point of the surface, the formation of rich layers and diverse forms of sunshine sports organizations and activities.

- The project gradually establishes and improves the sunshine sports instructors on the students sunshine sports guidance, supervision and evaluation mechanism so that ensure the planning and development guidance, the activities of the process of supervision, assessment and inspection indicators, increase recognition efforts to carry out students in the sun sports performance Of the collective and individual reward.

\section{ACKNOWLEDGMENT}

I'd like to show my sincere thanks to all those who have helped me to write the thesis. Firstly, I have to say thanks to my colleagues and friends who support me for a long time and who have looked over my thesis with patience and given me instructive suggestions. I extremely appreciate my family's support. I really appreciate Professor He's support. Thanks to his guidance and encouragement, I finish the paper finally after he looks over my paper and gives some good pieces of advice. Without his patient and consistent instruction, this paper could not have finished its present form.

Besides, I really appreciate my family's support. It is impossible for me to finish the paper without my wife's help and understanding. Thanks a lot. 


\section{CONCLUSION}

In order to completely implement the education policy of the overall development of physical and moral quality, we should try our best to promote and perfect the quality education through Sunshine Sports. Colleges should be in accordance with the laws and regulations and form system construction, team construction, funds investment, etc. We need to establish sports facilities equipped with hardware and security work so that we can keep the student accident from harm, offer the school liability insurance, carry out students accident prevention system and emergency response mechanism, and strengthen the students' healthy physical examination work.

In accordance with the guiding ideology of "healthy first" to improve students' physical health, we will have been working hard to promote students' sunshine and sports activities in an in-depth way, Sticking to the scientific teaching method of physical education and guide students to actively participate in group sports activities. At the same time we will further carry out the one-hour daily exercise program to improve the physical fitness of our students and make students promote overall and harmonious development of students' physical quality.

\section{REFERENCES}

[1] Tianlong zhong, Operation and Management of Sport -Theory and Practice [M], Fudan University Press, 2007, 4.

[2] Dongxing Xie, "Predicament of university sports during the social transformation period," Journal of Shangdong Institution of Physical Education and Sports, 2015 (4), pp. 102-107.

[3] Zheng Lei and Yong Wu, "Status Analysis and Recommendation for University Sports Associations to Promote the Development of 'Sunny Sports", Journal of Anhui Normal University, vol. 39. 2015(4), pp. 6872.

[4] H Jing, "The Study on the Long-Term Mechanism to Promote Sunny Sport in Colleges and Universities in Multi-Perspectives", Journal of Jilin Institute of Physical Education, vol. 36 .2012(4), pp. 82-85.

[5] Juan Sun and Jianghong Wang, "The existing problems and solving path in jointly organizing the top-level sport teams by school and enterpris," Journal of Liaoning Normal University (Natural science edition), 2012(1), pp.101-105.

[6] Wei Tong and Xuefeng Ren, "Exploration on the Construction of Scientific Style Curriculum System of Graduate Student Major in National Traditional Sport," Journal of Gansu Lianhe University(Natural Science Edition), 2008(2), pp.23-26.

[7] Weiliang Zhou, "Research on Curriculum Setting of the Specialty Theoretical Curriculum and the Textbook Writing in the Undergraduate of Nationality Traditional Sports in China", Journal of Beijing Sport University, 2005(8), pp.11-14.

[8] Hanyan Song and Jingong Zhang, "A Situation Analysis and Solutions of Collegiate Physical Education Industrialization Development", Journal of Institute of Disaster-Prevention Science and Technology, 2007(3), pp.32-36. 